\title{
Mastoid Bone involved by Pleomorphic Adenoma
}

\author{
${ }^{1}$ Hemanth Vamanshankar, ${ }^{2}$ Pradipta K Parida
}

\begin{abstract}
Pleomorphic adenoma is a benign tumor of the salivary glands, most commonly affecting the parotid gland. Pleomorphic adenoma of the ear is rare. The use of imaging modalities, especially magnetic resonance imaging (MRI), is particularly useful in localizing and surgical planning of these tumors. We present a case of pleomorphic adenoma invading the mastoid cortical bone, with review of literature.
\end{abstract}

Keywords: Cortical mastoidectomy, Mastoid bone, Pleomorphic adenoma.

How to cite this article: Vamanshankar $\mathrm{H}$, Parida PK. Mastoid Bone involved by Pleomorphic Adenoma. Int J Otorhinolaryngol Clin 2016;8(3):111-112.

\section{Source of support: Nil}

Conflict of interest: None

\section{CASE REPORT}

A 30-year-old male patient presented to the outpatient department with complaints of swelling behind the left ear, left ear decreased hearing, and tinnitus since the past 4 months. There was a history of a similar swelling behind the left ear 2 years earlier, for which he had undergone surgery, the details of which were unavailable with the patient. Physical examination revealed a swelling of about $3 \times 3 \mathrm{~cm}$ posterior and superior to the left ear, causing obliteration of the postauricular groove. A postaural scar of the previous surgery was seen (Fig. 1). There was no local rise in temperature or tenderness over the swelling. The swelling was firm in consistency and mobile along the horizontal plane. Skin over the swelling was pinchable. Left ear tympanic membrane was found to be normal. Pure tone audiometry showed a mild conductive hearing loss of $30 \mathrm{db}$ in the left ear. Examination of the opposite ear was found to be normal.

We proceeded to do a high-resolution computed tomogram of the temporal bone. This showed a hypodense soft tissue lesion in the lateral part of the left temporal

\footnotetext{
${ }^{1}$ Senior Resident, ${ }^{2}$ Associate Professor

${ }^{1,2}$ Department of Otorhinolaryngology, Head and Neck Surgery Jawaharlal Institute of Postgraduate Medical Education and Research, Puducherry, India

Corresponding Author: Hemanth Vamanshankar, Senior Resident, Department of Otorhinolaryngology, Head and Neck Surgery, Jawaharlal Institute of Postgraduate Medical Education and Research, Puducherry, India, Phone: +91-9940243408 e-mail: vhemanth2000@yahoo.com
}

bone, causing erosion of the mastoid air cells posteriorly and extending close to the sigmoid plate. Laterally, it was extending to involve the soft tissue superior to the pinna (Fig. 2). On performing magnetic resonance imaging (MRI), the lesion was hyperintense on T2-weighted images and isointense on T1. The lesion measured $2.5 \times$ $2.7 \mathrm{~cm}$ in dimensions (Fig. 3).

The patient was planned for a mastoid exploration under general anesthesia (Fig. 4). On entering the mastoid, the tumor was found to infiltrate the mastoid cavity. Dural and sigmoid sinus plates were found to be intact; fallopian canal was intact. A cortical mastoidectomy was done and the entire mass was removed in toto.

The specimen sent for histopathological examination showed features suggestive of pleomorphic adenoma. The

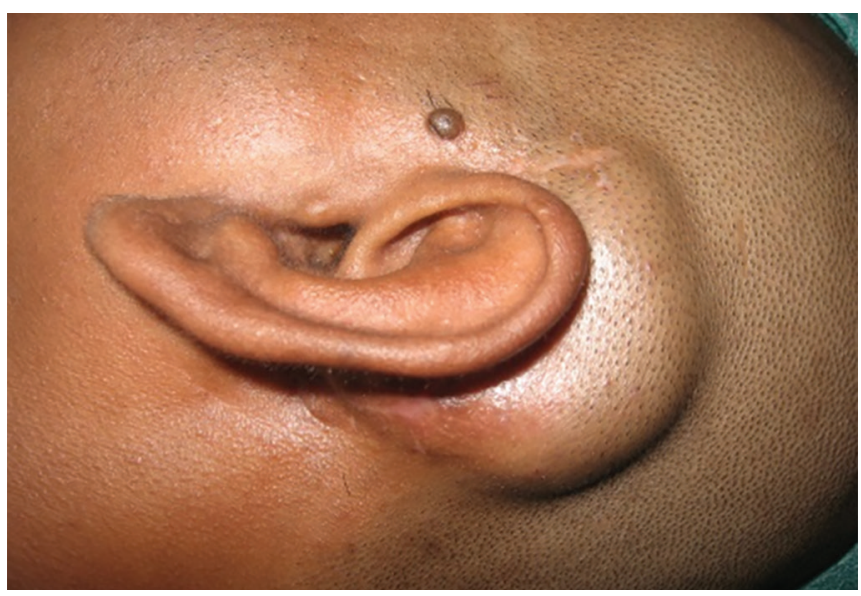

Fig. 1: Preoperative photograph of the mass posterior and superior to the left ear

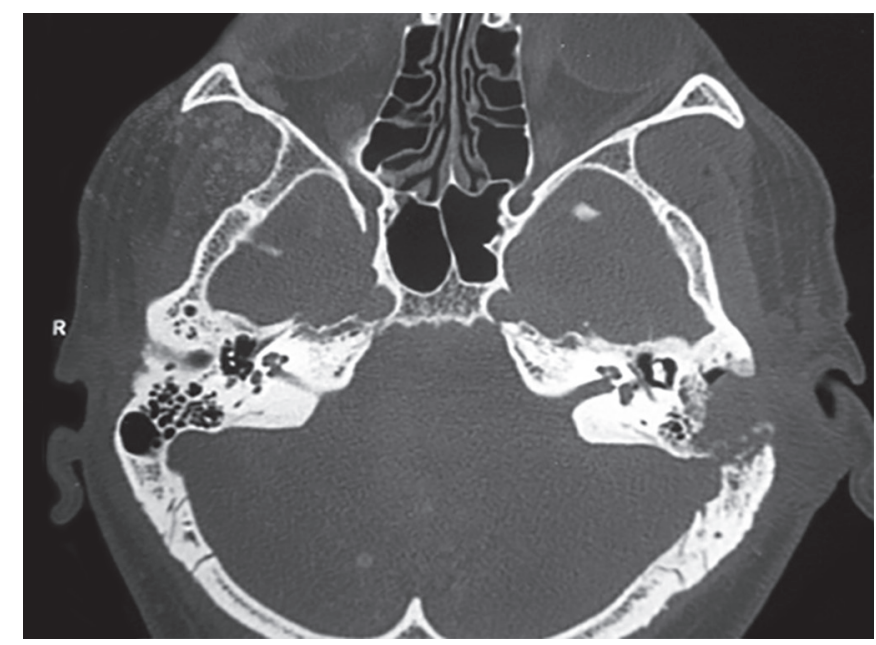

Fig. 2: High-resolution computed tomogram temporal bone, axial plane showing a hypodense soft tissue lesion in the lateral part of the left temporal bone, causing erosion of the mastoid air cells posteriorly 


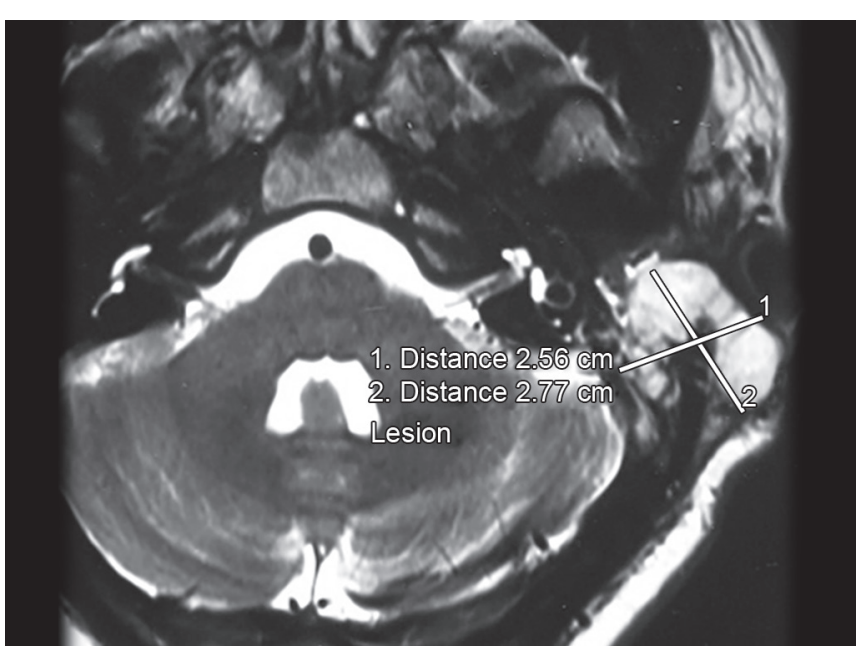

Fig. 3: Magnetic resonance imaging temporal bone, axial plane showing a hyperintense lesion measuring $2.5 \times 2.7 \mathrm{~cm}$ (T2-weighted image)

patient is now on regular follow-up and is asymptomatic for the past 6 months.

\section{DISCUSSION}

Pleomorphic adenoma is a benign tumor of the salivary glands, most commonly affecting the parotid gland. In view of its histological architecture being composed of both epithelial and mesenchymal elements, it is also commonly called as a "benign mixed tumor." Immunohistochemically, this tumor is composed of cytokeratin and S-100 protein deposited either focally or widespread. ${ }^{1}$ Treatment of pleomorphic adenoma is primarily surgical. However, recurrences are known to occur, even decades after primary surgery, with an incidence as high as $17 \% .^{2}$ This could be due to breech of the tumor capsule, spillage of tumor during surgery, or incomplete excision. ${ }^{3}$

Stennert et $\mathrm{al}^{3}$ found a higher proliferative index of the marker Ki-67 in pleomorphic adenomas of the aggressive type. Measurement of the nuclear antigen Ki-67 is a much more significant factor to determine the aggressive nature of the tumor. ${ }^{4}$ High expression of glycosylated phosphoprotein mucin 1 (MUC1) is also a known factor for recurrences. ${ }^{5}$

Pleomorphic adenoma of the ear is rare. The possible cause of its occurrence could be because of the presence of ceruminous glands in the external auditory canal, metaplasia of the middle ear mucosa, or presence of ectopic salivary glands. ${ }^{6}$ Extension of the tumor into the ear through the stylomastoid foramen from a previously operated pleomorphic adenoma of the parotid has also been described. ${ }^{7}$ Although described, the propensity to invade bone is also very rare. ${ }^{8}$ Limited invasion of the bone of the mastoid cortex was seen in our case.

The use of imaging modalities, especially MRI, is particularly useful in localizing and surgical planning

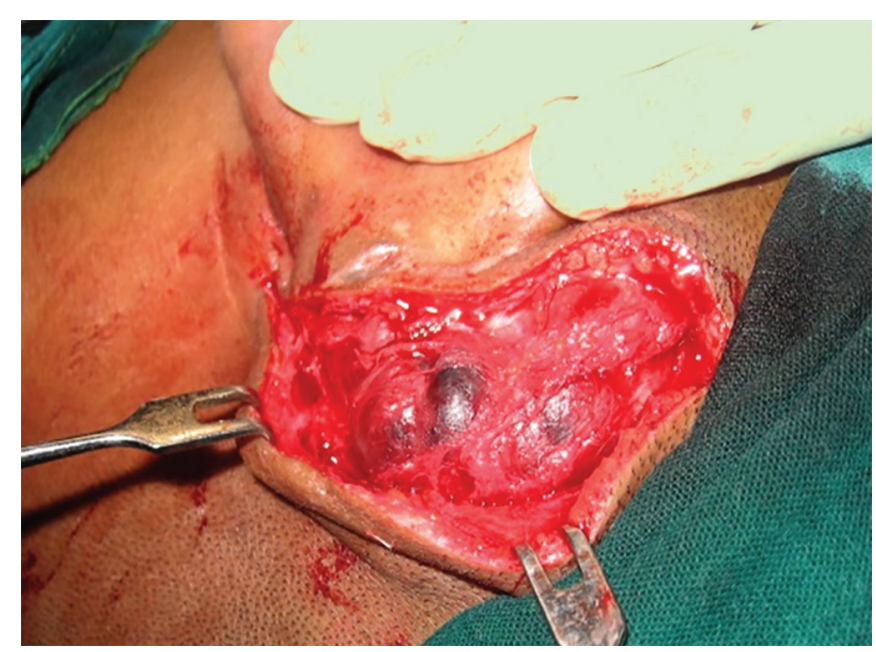

Fig. 4: Intraoperative photograph showing the mass on making postaural incision

of these tumors. The type of surgery done depends of the type of recurrence, patient's age, and the extent of previous surgery and has to be individualized from patient to patient. ${ }^{9}$

\section{REFERENCES}

1. Nardone M, Ferrara G, Nappi O, Di Maria D, Villari G. Pleomorphicadenoma in unusual anatomic sites: case reports and review of literature. Acta Otorhinolaryngol Ital 2002 Jun;22(3):158-163.

2. Suh MW, Hah JH, Kwon SK, Jung YH, Kwon TK, Kim KH, Sung MW. Clinical manifestations of recurrent parotid pleomorphic adenoma. Clin Exp Otorhinolaryngol 2009 Dec;2(4):193-197.

3. Stennert E, Wittekindt C, Klussmann JP, Arnold G, GuntinasLichius O. Recurrent pleomorphic adenoma of the parotid gland: a prospective histopathological and immunohistochemical study. Laryngoscope 2004 Jan;114(1):158-163.

4. Luukkaa H, Klemi P, Leivo I, Vahlberg T, Grénman R. Prognostic significance of Ki-67 and p53 as tumor markers in salivary gland malignancies in Finland: an evaluation of 212 cases. Acta Oncol 2006;45(6):669-675.

5. Hamada T, Matsukita S, Goto M, Kitajima S, Batra SK, Irimura T, Sueyoshi K, Sugihara K, Yonezawa S. Mucin expression in pleomorphic adenoma of salivary gland: a potential role for MUC1 as a marker to predict recurrence. J Clin Pathol 2004 Aug;57(8):813-821.

6. Peters BR, Maddox HE 3rd, Batsakia JG. Pleomorphic adenoma of the middle ear and mastoid with posterior fossa extension. Arch Otolaryngol Head Neck Surg 1988 Jun;114(6):676-678.

7. Benoit MM, Handzel O, McKenna MJ, Deschler DG. A 42-year-old man with facial nerve weakness and multiple recurrent pleomorphic adenoma. Otol Neurotol 2010 Sep;31(7):1157-1159.

8. Yasumoto M, Sunaba K, Shibuya H, Kurabayashi T. Recurrent pleomorphic adenoma of the head and neck. Neuroradiology 1999 Apr;41(4):300-304.

9. Glas AS, Vermey A, Hollema H, Robinson PH, Roodenburg JL, Nap RE, Plukker JT. Surgical treatment of recurrent pleomorphic adenoma of the parotid gland: a clinical analysis of 52 patients. Head Neck 2001 Apr;23(4):311-316. 